\title{
CdO:Ag İnce Filmlerinin SILAR Tekniği İle Büyütülmesi ve Karakterizasyonu
} Growth And Characterization CdO:Ag Thin Films By SILAR Technique

\author{
Demet İSKENDEROĞLU* ${ }^{* 1, a}$, Harun GÜNEY ${ }^{2, b}$ \\ ${ }^{1}$ Atatürk Üniversitesi, Doğu Anadolu Yüksek Teknoloji Uygulama ve Araştırma Merkezi, 25240, Erzurum \\ ${ }^{2}$ A ğrı İbrahim Çeçen Üniversitesi, Merkezi Uygulama ve Araştırma Laboratuvarı, 04100, Ağrı
}

• Geliş tarihi / Received: 02.12.2017 • Düzeltilerek geliş tarihi / Received in revised form: 28.06.2018 • Kabul tarihi / Accepted: 03.07 .2018

Öz

Yapılan çalışmada gümüş $(\mathrm{Ag})$ katkılı kadmiyum oksit $(\mathrm{CdO})$ ince filmleri mikroskobik cam yüzey üzerine Ardışık İyonik Tabaka Adsorpsiyon ve Reaksiyonu (SILAR) yöntemi ile oda sıcaklığında büyütülmesi gerçekleştirilmiş̧ir. Büyütülen numunelerin yapısal, optik ve morfolojik özellikleri incelenmiştir. Yapısal incelemede X-Işını Kırınımı (XRD) cihazı kullanılmış, XRD sonuçlarından numunelerin polikristal kübik yapıda olduğu ve ortalama kristal boyutunun Ag katkısı ile 22 nm'den ve 25 nm'ye arttığı görülmüştür. Soğurma ölçümleri, Ag katkı oranının artışı ile band aralığının $2.22 \mathrm{eV}$ 'den 2.67 eV'ye arttığını göstermiştir. Taramalı Elektron Mikroskopisi (SEM) görüntüleri Ag katkı oranı değişiminin yüzeyde değişime neden olduğunu ortaya koymuştur.

Anahtar kelimeler: Ag katk1, CdO, SILAR

\begin{abstract}
In the study, Ag-doped CdO thin films were grown on the microscopic glass surface by SILAR method at room temperature. The structural, optical and morphological properties of the grown film were investigated. XRD device was used in the structural investigation, XRD results show that the samples have polycrystalline cubic structure and the average crystal sizes have been shown rising from $22 \mathrm{~nm}$ to $25 \mathrm{~nm}$ with Ag dopant. The absorbance measurements show that the band gap increase from $2.22 \mathrm{eV}$ to $2.67 \mathrm{eV}$ with the increasing Ag dopant ratio. SEM images show that the changing Ag dopant ratio causes the significant changing in the surface of samples.
\end{abstract}

Keywords: Ag dopant, CdO, SILAR

\footnotetext{
*a Demet İSKENDEROĞLU; dmtttr@gmail.com; Tel: (0442) 23170 01; orcid.org/0000-0002-6889-8115

${ }^{b}$ orcid.org/0000-0001-9877-2591
} 


\section{Giriş}

Şeffaf iletken oksitler (TCO) elektronik endüstrilerindeki ve fotovoltaik cihazlardaki potansiyel uygulamaları nedeniyle çokça araştırılmıştır (Das ve Mitra, 2017). TCO üyesi olan $\mathrm{CdO}$ özellikle son birkaç yıldır güneş pili, optoelektronik uygulamaları, fototransistörler, fotodiyot uygulamaları ve gaz sensör üretimi gibi uygulamalarda yüksek elektrik iletkenliği, yüksek doğrusal refraktif indeks değeri, taşıyıcı yoğunluğu ve elektromanyetik spektrumun görünür aralığında yüksek geçirgenliği gibi sahip olduğu özelliklerinden dolayı bilim adamları tarafindan kullanılmıştır (Ali, 2017; Abbas vd., 2018). Katkılı ve katk1sız CdO ince filmleri farklı yöntemlerle büyütülebilmektedir. Püskürtme (Ferro ve Rodriguez, 1999), kimyasal buhar birikimi (Li vd., 2001), termal buharlaşma (Dakhel ve Henari, 2003), sol-jel (Aksoy vd., 2009), puls lazer birikimi (Gupta vd., 2009) ve SILAR (Salunkhe ve Lokhande, 2008; Güney ve İskenderoğlu, 2017) yöntemleri bunlardan bazılarıdır. SILAR yöntemi diğer yöntemlere nazaran bazı üstünlüklere sahiptir. Bunlardan bazılar1;

(i) Katkılama işlemi diğer metotlara göre daha kolaydır,

(ii) Yüksek kalitede alttaş ve vakum gerektirmemektedir,

(iii) Büyüme oranı ve filmin kalınlığı, kolaylıkla kontrol edilebilir.

(iv) Oda sıcaklığında yapılan işlemlerle, daha az sağlıklı malzemeler üzerine film büyütülebilir.

(v) Büyütülen materyal için zararlı olabilecek derecede isınmalara yol açmaz,

(vi) Altlık malzeme, boyutlar ve onun yüzey profili ile ilgili neredeyse hiçbir sınırlama yoktur.

(vii) Ucuz, basit ve geniş alanda büyütme yapmak için kullanışlıdır (Astam, 2010).

Bununla birlikte SILAR yönteminin birtakım dezavantajları da vardır:

(i) Özellikle gaz fazı büyütme yöntemlerine göre SILAR ile film büyütmek uzun zaman almaktadir,

(ii) Büyütülen filmler istenmese dahi oksijen kirliliği içerir,

(iii) Çözeltilerin aşırı derecede asidik ve bazik olduğunda bu çözeltilere dayanıksız olan alttaş malzemeler kullanılamaz (Astam, 2010).
Literatürde $\mathrm{CdO}$ ince filmleri ve nanoyapılarının SILAR yöntemi ile yapılan çalışmaları mevcuttur. Diğer çalışmalar genellikle katodik çözeltinin $\mathrm{pH}$ değeri ayarlanıp yapılmış veya çözelti sıcaklığı oda sıcaklığının üzerinde ve $80{ }^{\circ} \mathrm{C}$ ve üzeri sıcaklıklarda gerçekleştirilmiştir (Aydin ve Şahin, 2017; Shameem vd., 2017). Oda sıcaklığında gerçekleştirilmesi bizim çalışmamızı diğerlerinden ayırmaktadır. Ayrıca yaptığımız çalışmada, katk1 olarak gümüs $(\mathrm{Ag})$, çeşitli üstün özellikleri nedeniyle yaygın olarak kullanılan metalik bir element, genel katkılama yöntemi ile kolayca oksitlenebilen aktif bir metal olduğu ve oda sıcaklığında bile kolayca çözelti içerisinde dağılabildiği için seçilmiştir (Sivakumar vd., 2015). Yaptığımız çalışmada oda sicaklığında Ag katk1lı CdO ince filmlerinin cam altlık üzerine SILAR yöntemi ile büyütülmesi gerçekleştirilmiştir.

\section{Materyal Metot}

Yapılan çalışmada altlık olarak cam kullanılmıştır. Cam altlık büyütme işlemi gerçekleştirilmeden önce sirasiyla ultrasonik banyoda 300'er saniye (sn.) sürelerde $1 / 5$ oranında seyreltilmiş sülfürik asit $\left(\mathrm{H}_{2} \mathrm{SO}_{4}\right)$, etanol $\left(\mathrm{CH}_{3} \mathrm{CH}_{2} \mathrm{OH}\right)$ ve deiyonize (DI) su içerisinde temizlenmiştir.

Ag katkı1ı CdO ince filmlerinin SILAR yöntemi ile büyütülmesi işleminde bir döngüde katyonik ve anyonik çözeltileri kullanılmıştır. Katyonik çözelti olarak $50 \mathrm{ml} 0.1 \mathrm{M}$ kadmiyum nitrat tetrahydrate $\left(\mathrm{Cd}\left(\mathrm{NO}_{3}\right)_{2}+4 \mathrm{H}_{2} \mathrm{O}\right)$ kullanılmıştır. Katkı maddesi olan $\mathrm{Ag}$ için $0.1 \mathrm{M}$ gümüş nitrat $\left(\mathrm{AgNO}_{3}\right)$ çözeltisinden katyonik çözelti miktarının yüzdesel olarak $0.5 ; \quad 0.1$ ve 0.2 oranlarında kullanılmıştır. Katkı maddesi Ag ilave edildikten sonra 600 sn. manyetik karıştırıcı ile karıştırılmıştır. Anyonik çözelti olarak da pH değeri amonyak $\left(\mathrm{NH}_{4} \mathrm{OH} \% 25\right.$ sulu) ile 11.2 değerine ayarlanmış $100 \mathrm{ml}$ deiyonize (DI) su 600 sn. karıştırılmış olarak kullanılmıştır. Katyonik ve anyonik çözeltiler deney süresince oda sicaklığında tutulmuştur. Bir döngüde; altlık olarak kullanılan temizlenmiş cam $30 \quad$ sn. süresince katyonik çözeltiye ve 30 sn. süresince de anyonik çözeltiye daldırılarak bekletilmiştir. Şekil 1'de bir tam döngünün temsili deney șeması gösterilmiştir. Deneyin tamamı 20 döngüde gerçekleştirilmiştir. Böylece Ag katkılı CdO ince filmleri oda sicaklığında cam altlık üzerine büyütülmüştür. Büyüme esnasında gerçekleşen reaksiyonun aşağıdaki Denklem 1'de gösterildiği gibi olduğu düşünülmektedir;

$\mathrm{Cd}\left(\mathrm{NO}_{3}\right)_{2}+2 \mathrm{NH}_{4} \mathrm{OH} \rightarrow \mathrm{Cd}(\mathrm{OH})_{2}(\mathrm{~s})+2 \mathrm{NH}_{4}^{+}+2 \mathrm{NO}_{3}^{-}$ 
Katk1 olarak $\operatorname{Ag}\left(\mathrm{NO}_{3}\right)_{2}$ çözeltisi katyonik çözeltiye bu çözelti miktarının yüzdesel olarak $0.5, \quad 0.1$ ve 0.2 oranlarında ilave edilerek katkılama işlemi gerçekleştirilmiştir. Büyütülen numuneler atmosferik ortamda $200{ }^{\circ} \mathrm{C}$ 'de yüksek sıcaklık firınında tavlandığında aşağıdaki Denklem 2'deki reaksiyon gerçekleştiği düşünülmektedir (Güney ve İskenderoğlu, 2017).

$$
\mathrm{Cd}(\mathrm{OH})_{2}(\mathrm{~s}) \rightarrow \mathrm{CdO}(\mathrm{s})+\mathrm{H}_{2} \mathrm{O}
$$

Böylelikle Ag katkılı CdO ince filmleri SILAR yöntemi ile cam altlık üzerine oda sıcaklığında büyütülmüştür.
İnce filmlerin yapısal özellikleri X-1şını kırınım desenleri yardımı ile incelenmiştir. X-1şını kırınım desenleri Panalytical Empyrean X-Ray difraktometresi ile oda sicaklığında $20^{\circ} \leq 2 \Theta \geq 60^{\circ}$ açı aralığında $0.05^{\circ}$ 'lik aralıklarla tarama gerçekleştirilmiştir. İnce filmlerin optik özellikleri Shimadzu UV-1800 marka UV-Vis Spektrofotometre cihazı ile $300 \mathrm{~nm}$ ile $800 \mathrm{~nm}$ aralığında $1 \mathrm{~nm}$ aralıklarla tarama gerçekleştirilmiștir. İnce filmlerin yüzey morfolojileri hakkında bilgi edinebilmek için Zeiss-Sigma300 marka SEM ile görüntü alımları gerçekleştirildi.

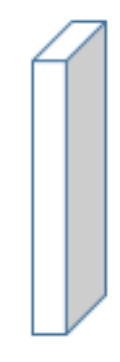

Cam

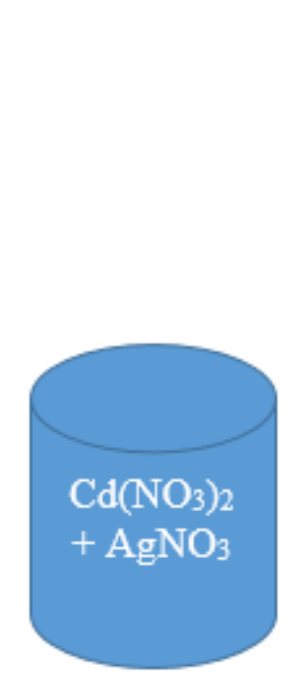

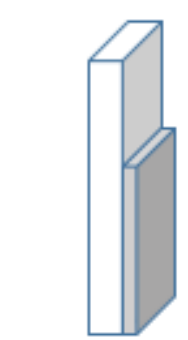

$\mathrm{Cam} / \mathrm{Cd}^{+2}+\mathrm{Ag}^{+}$

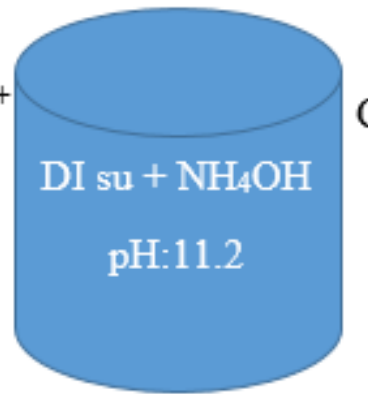

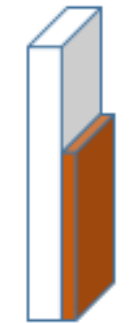

$\mathrm{Cam} / \mathrm{Cd}_{1-\mathrm{x}} \mathrm{Ag}_{\mathrm{x}}(\mathrm{OH})_{2}$

Şekil 1. Bir tam döngünün temsili deney şeması

\section{Bulgular ve Tartışma}

\subsection{XRD Analizi}

Büyütülen numunelerin oda sıcaklığında XRD ölçümleri alınmış ve sonuçlar Şekil 1'de verilmiştir. Şekil $2 \mathrm{Ag}$ katkılı $\mathrm{CdO}$ ince filmlerinin $2 \theta$ değeri 20 ve 60 derece arasında gerçekleştirilen XRD taramasını göstermektedir. Alınan XRD sonuçları ICSD standartları ve 03065-2908 kart numarasina göre tüm numunelerin kübik yapıda olduğunu göstermiştir. Şekil 2'de görüldüğü gibi katkısız ve $\mathrm{Ag}$ katkılı ince filmlerin XRD açıları ve düzlemleri yaklaşık ve sirasiyla; $33^{\circ}$ ve $(111), 38^{\circ}$ ve $(200), 55^{\circ}$ ve (220)'dir. ICSD standartları ve 03-065-2908 kart numarasına göre katkısız $\mathrm{CdO}$ pikleri ile benzer olan Şekil 2'de yer alan pikler bize numunelerin $\mathrm{Ag}$ katkısinın $\mathrm{CdO}$ ince filmlerinin kristal yapısına etki etmediğini ve yapı içerisine iyi uyum sağladığını göstermiştir (Güney ve İskenderoğlu, 2017). $\mathrm{Bu}$ durum ise yapıda $\mathrm{Ag}$ ile oluşabilecek oksitli yapıların oluşmadığını göstermektedir. Yani Ag katkısı hem kübik yapıya etki etmemiş hem de ilave bir pik oluşumuna neden olmamıștır. Fakat Tablo 1'de görüldüğü gibi pik pozisyonlarında Ag katkısı ile kayma gerçekleşmiştir. $\mathrm{Bu}$ kaymanın $\mathrm{Ag}$ ile $\mathrm{CdO}$ etkileşmesinden kaynaklanabileceği düşünülmek-tedir (Zhu vd., 2016). Literatürde yer alan farklı yöntemlerde de aynı şekilde Ag katkılı $\mathrm{CdO}$ numunelerinde aynı pikler gözlenmiş numunelerin kübik yapıda olduğu tespit edilmiş ve Ag piki gözlenememiştir (Sivakumar vd., 2015; El-Kemary vd., 2018).

Numunelerin XRD pik sayısal verileri kullanılarak kristal boyutunu $(D)$ ve ortalama kristal boyutunu $\left(D_{o r t}\right)$ hesaplamak için Denklem 3 'te gösterilen Scherer formülü kullanılmıştır; 


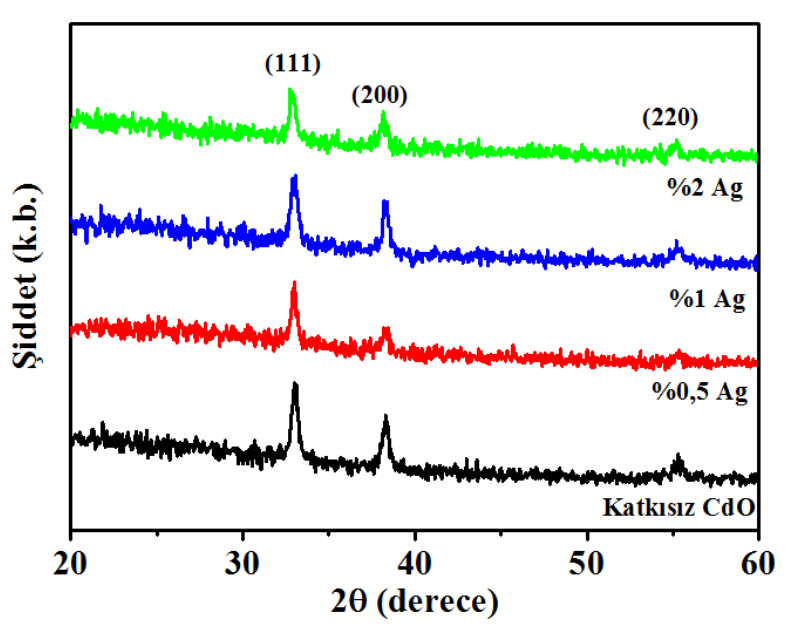

Şekil 2 Katkısız ve Ag katkılı $\mathrm{CdO}$ ince filmlerinin XRD ölçüm grafiği

$D=\frac{0.94 \lambda}{\beta \cos \theta}$

burada $\lambda$, dalga boyu $(0.15406 \mathrm{~nm}), \quad \beta$ maksimumun yüksekliğin yarı genişliği (FWHM) ve $\theta$ piklerin açı değeridir. Denklem 3 yardımı ile her $h k l$ düzlemi için $D$ değerleri hesaplanmış ve her katkı için alınan $D_{\text {ort }}$ neticesinde katkısız ve Ag katk1lı CdO ince filmlerinin $D$ değerleri $22 \mathrm{~nm}$ ve $25 \mathrm{~nm}$ olarak hesaplanmış ve Tablo 1'de gösterilmiştir. Yapılan $D_{\text {ort }}$ ve $D$ hesaplama sonuçları Tablo 1'de verilmiş̧ir. Böylece $\mathrm{Ag}$ katkısının $\mathrm{CdO}$ ince filmlerinin kristal boyutlarına çok fazla etki etmediği ve kristal yapısında ciddi değişime neden olmadığı düşünülebilir. Fakat yine de katkısız CdO ince filminin $D$ değerinin $22 \mathrm{~nm}$ iken Ag katkılı olan $\mathrm{CdO}$ ince filmlerinin $D_{\text {ort }}$ değerlerinin 24 ve 25 olması kristallğin iyileşmesi olarak yorumlanabilir (Sivakumar vd., 2015). Sivakumar vd., (2015) yaptıkları çalışmalarında bizim bulduğumuz tanecik boyutuna yakın katkısız CdO nanopartikülleri için $21 \mathrm{~nm}$ bulmuş olmalarına rağmen, Ag katkısı ile birlikte yaklaşık iki katı değeri bulmuşlardır. $\mathrm{Bu}$ durumun oluşmasında ince filmlerin büyütme yönteminin etkili olduğu düşünülmektedir. Fakat Mohanraj vd., (2018) mikrodalga 1şıması yöntemiyle yaptıkları çalışmalarında ise katkısız $\mathrm{CdO}$ nanopartikülleri $D$ değerlerini $35 \mathrm{~nm}$ ölçmüş iken ,Ag katkısı ile bu değerin 22 nm'ye kadar düştüğünü gözlemlemişlerdir. Diğer çalışmalarda elde edilen numunelerin de kübik yapıda olmasına rağmen bu değişimlerin büyütme yöntemlerinin farklılı̆ğndan kaynaklı olduğu düşünülmektedir. Büyütülen numunelerin düzlemler arası uzaklığ (d) Denklem 4'de verilen Bragg kanunu ile hesaplanmış ve Tablo 1'de gösterilmiştir. $n \lambda=2 d \sin \theta 4$

Yapılan hesaplamalarda çıkan $d$ sonuçları ICSD standartları ve 03-065-2908 kart numarasinda yer alan $d_{0}$ sonuçlarına yakınlık göstermektedir. Bu da SILAR yöntemi ile büyütülen katkısız ve $\mathrm{Ag}$ katk1lı CdO numunelerinin literatürde yer alan kristal değerlerine yakın olduğunu ve numunelerin kristal kalitesinin iyi olduğunu göstermektedir (Mohanraj vd., 2018).

Katkısız ve Ag katkılı CdO ince filmlerin yapılanma katsayıları (TC), ince filmlerin belirli düzleminin dokusu için Denklem 5 kullanılarak hesaplandı ve sapma, birliğin tercih edilen büyümeyi ima ettiğini gösterdi.

$T C(h k l)=\frac{I(h k l) / I_{0}(h k l)}{N^{-1} \sum_{N} I(h k l) / I_{0}(h k l)}$

Burada I (hkl) ölçülen pik şiddeti, I0 (hkl) veri kartının standart pik şiddeti, N yansıma sayısıdır. Tercihli yönelim için yapılan TC katkısız ve Ag katk1lı CdO ince filmlerinde olmas1 gereken 1 değerinde büyük olma şartını sağlamaktadır (Astam 2016).

İnce filmlerin optik bazı özellikleri hakkında bilgi sahibi olabileceğimiz yöntemlerden basit ve önemli bir ölçüm olan soğurma ölçümleri $\mathrm{Ag}$ katkılı CdO ince filmlerimiz için 300 ile $800 \mathrm{~nm}$ dalga boyları arasında alınmış ve sonuçları Şekil 3 a'da gösterilmiştir. Ag katkıll $\mathrm{CdO}$ ince filmlerin band aralıklarının tespiti soğurma ölçümleri aşağıda verilen Denklem 6 yardımı ile band aralığı direkt band aralığına sahip malzemeler için verilen formül ile hesaplanmıştır.

$(\alpha h v)=B\left(h v-E_{g}\right)^{1 / 2}$

burada $\alpha$ soğurma katsayısı, $E_{g}$ optik band aralığı ve $B$ sabit (Majid vd., 2013). Denklem 6 ile gerçekleştirilen hesaplamalar sonucunda çizilen Şekil 3 b'de soğurma katsayısının karesine karşı enerji grafiği elde edilmiștir ve sonuçlar Tablo 1'de gösterilmiştir. Tablo 1'de görüldüğü gibi katkısız olarak büyütülen $\mathrm{CdO}$ ince filminin band aralığ $2.22 \mathrm{eV}$ bulunmuştur. Bu sonuca benzer sonuç Maswanganye vd., (2014) tarafindan sol-jel metodu ile yapılan çalışmalarında $2.23 \mathrm{eV}$ olarak bulunmuştur. Yine aynı çalışmada Ag artışı ile band aralığında artış gerçekleşmiştir. 
Tablo 1. Katkısız ve Ag katkılı CdO numunelerinin hesaplanan band aralığı, $h k l, 2 \theta$, FWHM, $D$, $D_{\text {ort }}, d, d_{0}$ ve $T C$ değerleri.

\begin{tabular}{cccccccccc}
\hline $\begin{array}{c}\text { Numune } \\
\text { Ad1 }\end{array}$ & $\begin{array}{c}E_{g} \\
(\mathrm{eV})\end{array}$ & & $\begin{array}{c}2 \theta \\
\left({ }^{\circ}\right)\end{array}$ & FWHM & $\begin{array}{c}D \\
(\mathrm{~nm})\end{array}$ & $\begin{array}{c}D_{\text {ort }} \\
(\mathrm{nm})\end{array}$ & $\begin{array}{c}d \\
(\AA)\end{array}$ & $\begin{array}{c}d_{0} \\
(\AA)\end{array}$ & $\begin{array}{c}T C \\
(\mathrm{hkl})\end{array}$ \\
\hline & & $(111)$ & 33.0001 & 0.4833 & 18 & & 2.7122 & 2.7088 & 1.2399 \\
Katkısız & 2.22 & $(200)$ & 38.2763 & 0.4082 & 22 & 22 & 2.3496 & 2.3459 & 0.8855 \\
CdO & & $(220)$ & 55.3010 & 0.3713 & 25 & & 1.6599 & 1.6588 & 0.8746 \\
& & $(111)$ & 32.9727 & 0.2686 & 32 & & 2.7144 & 2.7088 & 1.3889 \\
$\% 0.5 \mathrm{Ag}$ & 2.51 & $(200)$ & 38.1940 & 0.4906 & 18 & 24 & 2.3544 & 2.3459 & 0.7600 \\
& & $(220)$ & 55.3238 & 0.4322 & 22 & & 1.6592 & 1.6588 & 0.8511 \\
& & $(111)$ & 33.0921 & 0.4802 & 18 & & 2.7048 & 2.7088 & 1.1132 \\
$\% 1 \mathrm{Ag}$ & 2.58 & $(200)$ & 38.1668 & 0.2466 & 36 & 24 & 2.3561 & 2.3459 & 0.9793 \\
& & $(220)$ & 55.2077 & 0.4933 & 19 & & 1.6624 & 1.6588 & 0.9075 \\
& & $(111)$ & 32.7287 & 0.3634 & 24 & & 2.7340 & 2.7088 & 1.0555 \\
$\% 2 \mathrm{Ag}$ & 2.67 & $(200)$ & 38.1668 & 0.3634 & 24 & 25 & 2.3561 & 2.3459 & 0.9497 \\
& & $(220)$ & 55.2076 & 0.3635 & 26 & & 1.6624 & 1.6588 & 0.9948 \\
\hline
\end{tabular}

Ag katk1lı ince filmlerin $E_{g}$ değerleri Şekil 3 b'de $\alpha=0$ değerinde karşllık gelen enerji ile tespit edilmiştir. $E_{g}$ değerleri Ag katkı oranının artışı ile artış göstermiştir. Majid vd., (2013) Ag katkılı $\mathrm{CdO}$ nanopartikülleri yaptıkları çalışmalarında $\mathrm{Ag}$ katkı oranının artışı ile band aralı̆̆ının artışı ve dolayısıyla maviye kayma gözlemlemişlerdir. Band aralığının katkısız CdO'a nazaran $\mathrm{Ag}$ oranının artışı ile artış göstermesinin nedeninin Burstein-Moss etkisi olabileceğini ve ayrıca bu artışa Ag taşıyıcı konsantrasyon artışının da neden olabileceğini belirtmişlerdir. Şekil 3 ve Tablo 1'den katk1sız ve $\mathrm{Ag}$ katk111 $\mathrm{CdO}$ ince filmlerinin soğurma ölçümlerinin ve band aralıklarının görünür bölgede olması ve band aralıklarının $\mathrm{Ag}$ ile değiştirilebilmesi ve bunun sonucunda elektriksel iletkenliğinin de değişmesi bu numunelerin optoelektronik cihazlarda kullanılabileceğini göstermektedir (Ganesh vd., 2017). Katkısız ve $\mathrm{Ag}$ katkılı $\mathrm{CdO}$ ince filmlerinin $E_{g}$ değerlerindeki değişiklikler, Ag katkı oranının değişimi ile birlikte $\mathrm{CdO}$ ince filminin kristal yapısındaki değişmelere bağlı olabilir. Bu durum XRD sonuçları ile uyumludur. Ayrıca. nanoyapılı malzemelerde $E_{g}$ değişimi, kuantum boyutu etkisi ile açıklanabilir (Sivakumar vd., 2015).
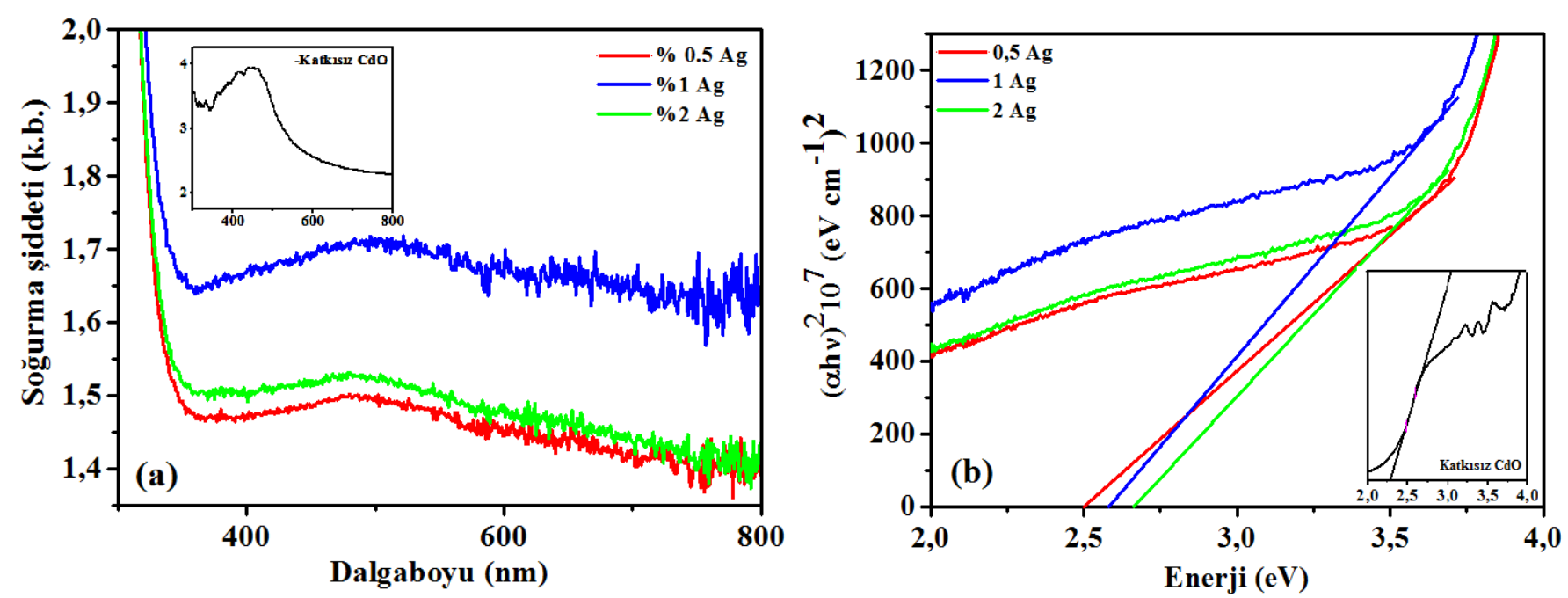

Şekil 3. Katkısız ve Ag katkılı CdO ince filmlerin a) soğurma b) band aralığı grafiği 


\subsection{SEM Analizi}

Optiksel, elektriksel vb. birçok özelliğin değişimini yansıtan ve malzemenin istenilen uygulama için kullanımına bir bakımdan uygun olup olmadığının tespitinde ön değerlendirme amaçlı kullanılabilen SEM son y1llarda gelişen cihaz teknolojisi ile araştırmacılara çok daha iyi görüntüler sunmaktadır. Yüzey morfolojilerinin Ag katkı oranına göre nasıl değiştiğini öğrenmek için katkısız ve $\mathrm{Ag}$ katkılı $\mathrm{CdO}$ ince filmlerinin SEM görüntüleri alınmış ve toplu olarak Şekil 4'de gösterilmiştir. Şekil 4'de Ag katkısı arttıkça numunelerin yüzey morfolojilerinin değişmekte olduğu görülmektedir. Aynı şekilde El-Kemary vd., (2014) yaptıkları Ag katkılı CdO çalışmalarında Ag katkısına bağlı olarak numunelerin yüzey morfolojilerinde değişim gözlemlemişlerdir. Şekil 4'te katkısız CdO numunelerinin nano duvar yapıya benzer yap1 oluşturduğu fakat $\mathrm{Ag}$ miktarının artışı ile birlikte bu yapının değiștiği, daha düzensiz ve dağınık bir yapıya dönüştügüü gözlenmektedir. Böylece $\mathrm{Ag}$ katkısının CdO yapısının yüzey morfolojisinde değişime neden olduğu söylenebilir. Sivakumar vd., (2015) kimyasal çökertme yönteminde yaptıkları \%1; \%2 ve \%3 Ag katkı1ı CdO ile bizim yaptığımız SILAR yöntemi ile kıyaslandığında; bizim yapılar daha çok nano duvara benzer yapıda iken, onların çalışmalarındaki yapılar küresel görüntülü yapıdadır. $\mathrm{Bu}$ durum dikkate alındığında numunelerin büyütme yöntemine göre yüzey morfolojileri farkl11ıklar sergilemektedir.
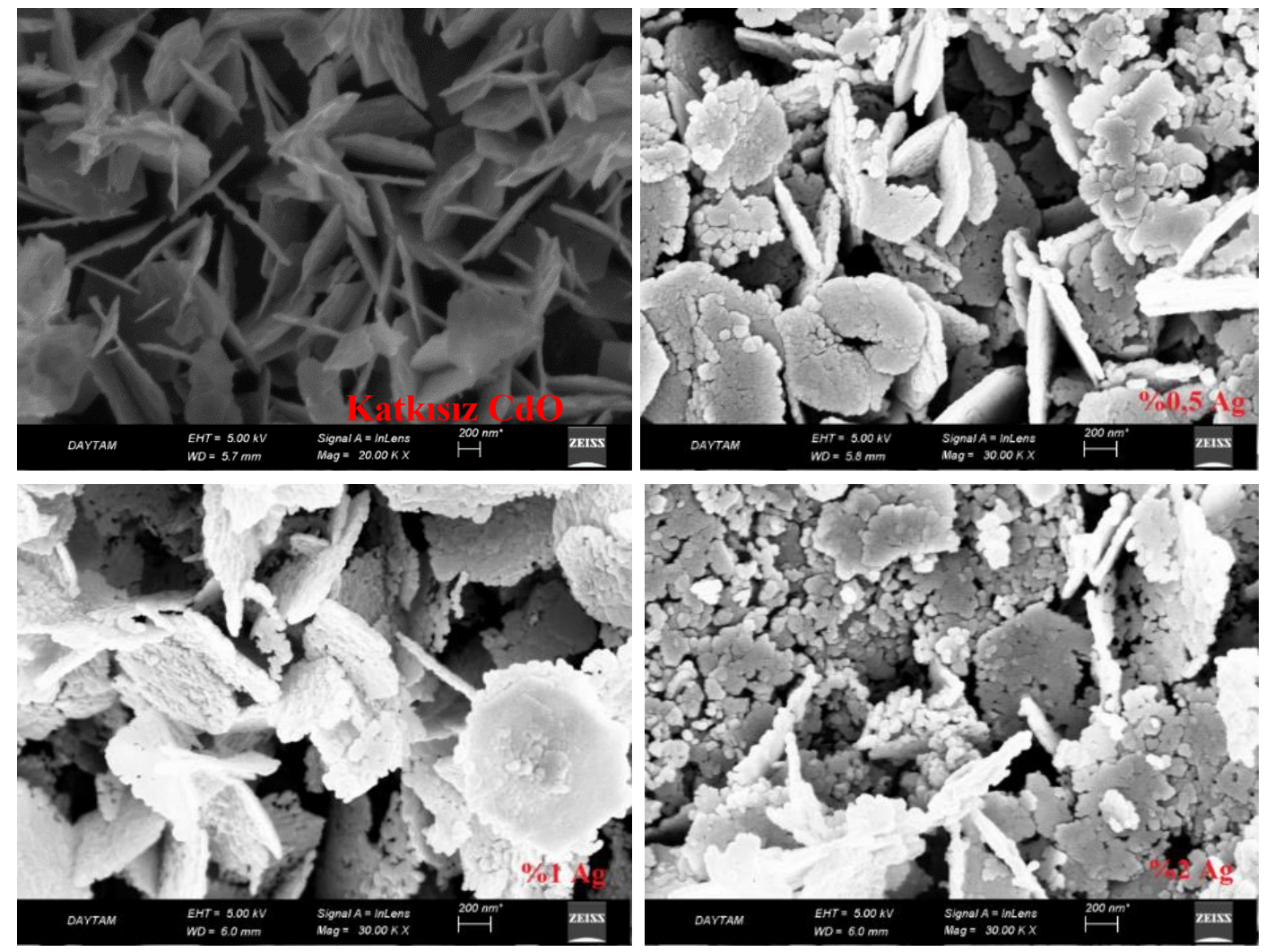

Şekil 4. Katkısız ve Ag katkılı CdO ince filmlerinin SEM görüntüleri

\section{Sonuçlar}

Burada yapılan çalışmada $\mathrm{Ag}$ katkı1ı $\mathrm{CdO}$ ince filmleri SILAR yöntemi ile başarılı olarak büyütülmüş ve yapısal, optik ve morfolojik özellikleri XRD, soğurma ve SEM ile incelenmiştir. Yapılan incelemelerde SILAR yöntemi ile büyütülen numunelerin kübik yapıda oldukları görülmüş, band aralığı değerleri $\mathrm{Ag}$ katk1 miktarına bağlı olarak ile 2.22 eV'den 2.67 eV'ye artış göstermiş ve yüzey morfolojisi de $\mathrm{Ag}$ katkısı ile değişim sergilemiştir. Ag katkısı ile optiksel özelliklerindeki değişim Ag katkı1ı CdO ince filmlerin optoelektronik cihazlarda uygulanma potansiyeline sahip olduğunu göstermektedir.

\section{Teşekkür}

$\mathrm{Bu}$ çalışma Ağrı İbrahim Çeçen Üniversitesi Bilimsel Araştırma Projeleri Birimi (Proje No: MYO.17.001) tarafından desteklenmiştir. 


\section{Kaynaklar}

Abbas, M., Tawfik, W. ve Chen, J., 2018. CdO Nanorods and $\mathrm{Cd}(\mathrm{OH})_{2} / \mathrm{Ag}$ Core/Satellite Nanorods: Rapid and Efficient Sonochemical Synthesis. Characterization and Their Magnetic Properties. Ultrasonics Sonochemistry, 40, 577-582.

Aksoy, S., Caglar, Y., Ilican, S. ve Caglar, M., 2009. Effect Of Heat Treatment on Physical Properties of CdO Films Deposited by SolGel Method. International Journal of Hydrogen Energy, 34(12), 5191-5195.

Ali, O., 2017. Study of Structural, Morphological and Optical Properties of Pure $\mathrm{CdO}$ and Ag:CdO Doped Thin Films on Glass Substrates with High Relatively Ag Concentrations (2.5\%. 5\% $10 \%$ and $15 \%)$ Prepared by Sol-Gel Method. Journal of Applied Physics, 9, 1-8.

Astam, A., 2010. SILAR yöntemiyle büyütülen CuxS ve CuxSey ince filmlerin arayüzey tabakalı sandviç yapılarda kullanılması ve karakteristik parametrelerinin incelenmesi, Doktora Tezi, Atatürk Üniversitesi Fen Bilimleri Enstitüsü. Erzurum, 129s.

Astam, A., 2016. Structural and optical characterization of $\mathrm{Cu}_{2} \mathrm{SnSe}_{3}$ thin films prepared by SILAR method. Thin Solid Films, 615, 324-328.

Aydin, R. ve Şahin, B., 2017. The role of Triton $\mathrm{X}-100$ as a surfactant on the $\mathrm{CdO}$ nanostructures grown by the SILAR method. Journal of Alloys and Compounds, 705, 9-13.

Dakhel, A.A. ve Henari, F.Z., 2003. Optical Characterization of Thermally Evaporated Thin CdO Films. Crystal Research and Technology, 38(11), 979-985.

Das, M.R. ve Mitra, P., 2017. Influence of Mn İncorporation on İonic Conductivity and Dielectric Relaxation Process in CBD Synthesized CdO Thin Films. Journal of Alloys and Compounds, 724, 614-624.

Ferro, R. ve Rodriguez, J.A., 1999. Some Physical Properties of F-Doped CdO Thin Films Deposited by Spray Pyrolysis. Thin Solid Films, 347(1-2), 295-298.
Ganesh, V., Shkir, M., AlFaify, S., Yahia, I.S., Zahran, H.Y. ve El-Rehim, A.F.A., 2017. Study on structural, linear and nonlinear optical properties of spin coated $\mathrm{N}$ doped $\mathrm{CdO}$ thin films for optoelectronic applications. Journal of Molecular Structure, 1150, 523-530.

Gupta, R.K., Ghosh, K., Patel, R. ve Kahol, P.K., 2009. Highly Conducting and Transparent Ti-Doped $\mathrm{CdO}$ Films by Pulsed Laser Deposition. Applied Surface Science, 255(12), 6252-6255.

Güney, H. ve İskenderoğlu, D., 2017. SILAR Yöntemi İle Büyütülen Katkısız ve $\mathrm{Zn}$ Katkılı CdO Yariiletken İnce Filmlerinin Yapısal, Optik ve Morfolojik Özelliklerinin İncelenmesi. Sakarya University Journal of Science, 21(6), 1544-1549.

El-Kemary, M., El-Mehasseb, I. ve El-Shamy, H., 2018. Ag-doped $\mathrm{CdO}$ nanocatalysts: Preparation, characterization and catechol oxidase activity. Journal of Molecular Structure, 1161, 83-88.

Li, X., Young, D.L., Moutinho, H., Yan, Y., Narayanswamy, C., Gessert, T.A. ve Coutts, T.J., 2001. Properties of CdO Thin Films Produced by Chemical Vapor Deposition. Electrochemical and SolidState Letters, 4(6), C43-C46.

Majid, A., Afzal, Z., Murtaza, S., Nabi, G. ve Ahmad, N., 2013. Synthesis and Characterization of Silver Doped Cadmium Oxide Nanoparticles. Journal of Advanced Physics, 2(2), 116-118.

Maswanganye M.W., Makgobela R.V., Rammutla K.E., Mosuang T.E. ve Mwakikunga B.W., 2014. The effect of silver (Ag) dopant on the structural and optical properties of sol gel prepared $\mathrm{CdO}$ nanoparticles, The 59th Annual Conference of the South African Institute of Physics, SAIP2014, 66-71.

Mohanraj, K., Balasubramanian, D., Chandrasekaran, J. ve Bose, A.C., 2018. Synthesis and characterizations of Agdoped $\mathrm{CdO}$ nanoparticles for $\mathrm{PN}$ junction diode application. Materials Science in Semiconductor Processing, 79, 74-91.

Salunkhe, R.R. ve Lokhande, C.D., 2008. Effect of Film Thickness on Liquefied Petroleum 
Gas (LPG) Sensing Properties of SILAR Deposited $\mathrm{CdO}$ Thin Films. Sensors and Actuators B: Chemical, 129(1), 345-351.

Shameem, A., Devendran, P., Siva, V., Raja, M., Bahadur, S.A., ve Manikandan, A., 2017. Preparation and characterization studies of nanostructured $\mathrm{CdO}$ thin films by SILAR method for photocatalytic applications. Journal of Inorganic and Organometallic Polymers and Materials, 27(3), 692-699.

Sivakumar, S., Venkatesan, A., Soundhirarajan, P. ve Khatiwada, C.P., 2015. Synthesis,
Characterizations and Anti-Bacterial Activities of Pure and Ag Doped Cdo Nanoparticles by Chemical Precipitation Method. Spectrochimica Acta Part A: Molecular and Biomolecular Spectroscopy, 136, 1751-1759.

Zhu, X., Wu, D., Wang, W., Tan, F., Wong, P.K., Wang, X., Qui, X. ve Qiao, X., 2016. Highly Effective Antibacterial Activity and Synergistic Effect of $\mathrm{Ag}-\mathrm{MgO}$ Nanocomposite Against Escherichia coli. Journal of Alloys and Compounds, 684, 282-290. 